\title{
EVALUASI KEBERHASILAN MANAJEMEN DALAM IMPLEMENTASI SISTEM ENTERPRISE RESOURCE PLANNING (ERP)
}

\section{Lutfi Alhazami}

Sekolah Tinggi Ilmu Ekonomi Media Nusantara Citra (STIE MNC), Indonesia

Email: alhazamilutfi@gmail.com

\begin{abstract}
This research aims to find out the factors that influence the successful implementation of ERP in PT. Innotek Indonesia. The data used is the primary data from the questionnaire being shared. This research was conducted in 13 units of partnership companies at PT Innotek Indonesia. 80 respondents. The sample method of this study is non-probability sampling quota sampling based on criteria. This study used regression analysis by testing the t and $F$ hypotheses. This research shows change management, project management, top management sponsorship, realistic scope setting, adequate budget and ERP education affect the success of ERP implementation. Simultaneously all these factors are also able to explain the association to the success of ERP implementation by 68\%. This research is expected to be a reference for companies that want to implement ERP to prepare and pay attention to all these factors for the success of ERP implementation.
\end{abstract}

Keywords: Enterprise Resources Planning (ERP); ERP implementation; determining factors of success

\begin{abstract}
Abstrak
Penelitian ini bertujuan untuk mengetahui faktor-faktor yang mempengaruhi keberhasilan implementasi ERP di PT. Innotek Indonesia. Data yang digunakan adalah data primer dari kuesioner yang dibagikan. Penelitian ini dilakukan pada 13 unit perusahaan partnership di PT Innotek Indonesia. Responden sebanyak 80 responden. Metode sampel penelitian ini adalah non-probability sampling quota sampling berdasarkan kriteria. Penelitian ini menggunakan analisis regresi dengan pengujian hipotesis $\mathrm{t}$ dan $\mathrm{F}$. Penelitian ini menunjukkan manajemen perubahan (change management), manajemen proyek (project management), dukungan manajer puncak (top management sponsorship), penetapan scope yang realistis, budget yang memadai dan edukasi ERP mempengaruhi keberhasilan implementasi ERP. Secara simultan semua faktor-faktor itu juga mampu menjelaskan keterkaitannya terhadap keberhasilan implementasi ERP sebesar 68\%. Penelitian ini diharapkan menjadi acuan bagi perusahaan yang ingin mengimplementasikan ERP untuk mempersiapkan dan memperhatikan semua faktor tersebut demi keberhasilan implementasi ERP.
\end{abstract}

Kata kunci: Enterprise Resources Planning (ERP); implementasi ERP; faktor penentu keberhasilan 
Coresponden Author

Email: alhazamilutfi@gmail.com

Artikel dengan akses terbuka dibawah lisensi

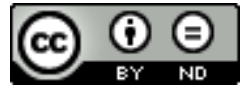

\section{Pendahuluan}

Penggunaan aplikasi komputer sudah diterapkan di berbagai bidang seperti bisnis. Banyak perusahaan yang proses binisnya menggunakan perangkat lunak berbasis komputer. Aplikasi ERP menjadi tulang punggung sebuah perusahaan yang memiliki kompleksitas operasional yang tinggi. Berjalannya waktu, tuntutan dalam penggunaan aplikasi Enterprise Resource Planning (ERP) dalam proses bisnis semakin besar terutama dalam mengintegrasikan antar departemen dan antar divisi. Sebelum adanya ERP, sistem masing-masing divisi berjalan sendiri-sendiri, tidak saling terhubung dan terintegrasi. Sebagai contoh, divisi keuangan menggunakan sistem akuntansi keuangan dengan aplikasi khusus keuangan. Divisi pemasaran dan penjualan membuat aplikasi sendiri melalui sistem pencatatan pemesanan. Bagian sumber daya manusia menggunakan sistem personalia sendiri, sehingga hal tersebut menyulitkan manajerial eksekutif untuk mendapatkan gambaran secara menyeluruh bagaimana operasi perusahaan berjalan (Winarno, 2010). Oleh sebab itu lahirlah ERP dengan sistem yang dapat melihat operasional perusahaan dalam satu aplikasi.

ERP seringkali diterapkan oleh perusahaan besar karena investasinya yang relative mahal. Namun investasi pada sistem ini memberikan keuntungan bagi perusahaan. Implementasi sistem ERP ini harus didukung oleh teknologi informasi dalam proses bisnis yang luarannya dapat menguragi biaya dan meningkatkan pendapatan sehingga mencapai kondisi optimum dalam meraih laba. Efektifitas implementasi sistem ERP sangat diharapkan agar investasi besar yang dilakukan tidak sia-sia.

PT. Folarium Innotek Indonesia adalah sebuah perusahaan pengembang software/software di bidang perencanaan sumber daya perusahaan yang saat ini sedang berkembang pesat khususnya di bidang konstruksi, manufaktur dan konsultasi. PT. Folarium Innotek Indonesia berkomitmen tinggi terhadap pengembangan sistem terintegrasi, menjalin kemitraan akademis dan industri dengan mengedepankan prinsip praktik integrasi data untuk menghasilkan teknologi yang lebih baik. Sejak tahun 2012 telah berkomitmen untuk membangun bisnis yang dapat memberikan nilai tambah bagi industri dengan teknologi terintegrasi. Klien dari PT. Folarium Innotek Indonesia adalah 1. PT. Astra Honda Motor-Reg. Jateng, 2. PT. WIKA Bangunan Gedung, 3. PT. Yudhistira Ghalia Indonesia, 4. Pusat Studi Transportasi \& Logistik UGM, 5. PT. Judin Makmur Sejahtera, 6. Habitat Property, 7. PT. Aquiva Gallery, 8. Beautysky Aesthetic Center, 9. KPRI Wana Mandiri, 10. Mitra Warna Batam, 11. Nasi Uduk Palagan, 12. Secret Garden Coffee \& Chocholate, dan 13. CV. Mitra Tani Abadi. Peneliti mengambil objek perusahaan ini karena ada penerapan sistem ERP yang dilakukan tidak selalu berhasil. Data perusahaan menunjukan bahwa tingkat ketidak berhasilan implementasi 
ERP mencapai 20\% sejak tahun 2014-2019. Kegagalan diindikasikan melalui mundurnya waktu go-live dari waktu yang sudah direncanakan, biaya yang tiba-tiba membengkak di awal implementasi, sampai pada pencapaian yang tidak baik dari key performance indicator yang sudah ditetapkan. Kendala ini disebabkan oleh 1 . Kurangnya dukungan dan komitmen dari top management dan user; 2. Manajemen perubahan didalam perusahaan, terkait dengan pribadi, organisasi, dan juga budaya seseorang maupun perusahaan; 3. Keterlibatan user dalam proyek; 4. Pelatihan dan pendidikan; 5. Tim yang terlibat dalam proyek; 6. Kurangnya persiapan dan jadwal yang kurang memadai. Kegagalan ini perlu dicegah oleh perusahaan, karena dampaknya akan mengganggu proyek implementasi ERP. Selain itu juga akan menurunkan nilai perusahaan dan kepercayaan di mata pengguna, serta akan merugikan perusahaan dalam jangka panjang. Oleh sebab itu, menarik untuk diteliti Faktor penyebab yang mempengaruhi keberhasilan implementasi sistem ERP yang telah banyak dilakukan.

Menurut Toruan (2013), Enterprise Resources Planning adalah sebuah sistem informasi yang terintegrasi yang bertujuan untuk meningkatkan kinerjanya di bidang penjualan dan pemasaran, pemeliharaan, produksi/manufakturing, gudang, logistik, keuangan dan sumber daya manusia. ERP dapat memudahkan akses semua data dari semua unit. Kelebihan dari ERP ini menurut Tjakrawala dan Lukita (2012), serta Toruan (2013) dikatakan bahwa ERP dapat memperbaiki layanan pelanggan, jadwal produksi lebih tepat, proses bisnis best practice, integrase yang real time, sebagai pengendalian, kecermatand dalam membuat jurnal akuntansi, pencatatan berdasarkan pada sumber transaksi dan mudah dalam pemakaiannya.

Di sisi lain, penggunaan ERP masih memiliki masalah yang kompleks. Menurut Toruan (2013), sistem ERP memiliki harga yang sangat mahal, memiliki kostumisasi biaya, biaya tahunan, biaya pelatihan karyawan dan waktu implementasi yang cukup lama. Semua permasalahan yang kompleks ini menjadi isu sampai saat ini di luar dari manfaat yang akan didapatkan dari pemakaian ERP. Keberhasilan sistem ERP terletak kepada bagaimana sistem ERP yang telah digunakan akan memenuhi kebutuhan yang ada pada bisnis perusahaan atau tidak serta apakah sistem ini mampu menyelesaikan masalah dan menjadi solusi dari bisnis tersebut atau tidak. Pada esensinya, ERP ini merupakan sistem yang dimanfaatkan untuk emperbesar tujuan organisasional. Kesuksesan sistem ERP terletak pada bagaimana cara perusahaan dan penggunanya mengadopsi sebuah sistem untuk menambah kefektifan dan efesiensian dalam organisasinya (Gable, Sedera, \& Chan, 2003).

Survei dari panorama consulting pada tahun 2010 dilaporkan bahwa, 57\% dari sistem ERP membutuhkan waktu lebih lama dari yang diharapkan untuk diterapkan, 54\% melebihi anggaran, 41\% gagal mencapai setidaknya setengah dari keuntungan bisnis mereka, dan $40 \%$ terputus. Sebanyak 32\% eksekutif dan 39\% karyawan tidak puas dengan penerapan sistem ERP perusahaan (Kimberling, 2015). Krigsman (2010) mengungkapkan 5 indikasi kegagalan proyek ERP. Pertama, Implementasi ERP membutuhkan waktu lebih lama dari yang diprediksi. Kedua, biaya implementasi ternyata lebih dari budget yang disediakan. Ketiga, sebagian besar implementasi ERP 
kurang memberikan nilai bisnis. Keempat, implementasi perangkat lunak sebagai layanan (software as a service - SaaS) membutuhkan waktu yang lebih cepat dibandingkan dengan implementasi ERP di tempat. Kelima, perusahaan tidak secara efektif mengelola perubahan organisasi pada saat implementasi ERP.

Biaya implementasi ERP berdasarkan Sasmoyo (2010) sekitar $43 \%$ biaya digunakan untuk proses re-engineering, sedangkan data conversation, hardware dan training membutuhkan rata-rata sekitar $15 \%$ dan sekitar $12 \%$ biaya implementasi ERP digunakan untuk Software. Biaya untuk skala Small- Medium berkisar diantara 30 ribu sampai 7 ratus Dollar Amerika. Skala Medium, berkisar dari 7 ratus sampai 3 Juta Dollar Amerika. Yang terakhir untuk skala besar adalah lebih dari 3 Juta Dollar Amerika. Selain biaya, hambatan lain dalam implementasi sistem ERP di unit bisnis MNC Grup, diantaranya adalah kurangnya dukungan dan komitmen dari top management dan user, Manajemen perubahan di dalam perusahaan seperti karyawan, struktur organisasi, budaya perorangan maupun perusahaan, keterlibatan user dalam proyek, pelatihan dan Pendidikan, tim yang terlibat dalam proyek implementasi ERP, kurangnya persiapan dan jadwal yang kurang memadai.

Adanya masalah yang sangat kompleks tersebut, tingkat keberhasilan ERP pada penerapannya masih rendah. Banyak perusahaan yang telah mengimplementasikan sistem ERP namun masih belum memanfaatkan seluruh potensi ERP dalam perusahaannya. Krigsman (2010) melaporkan bahwa tingkat kegagalan proyek teknologi informasi adalah berkisar antara 30-70\% dan bahkan menurut Kanaracus, (2010) dan Kimberling (2015) beberapa perusahaan yang gagal mengimplementasikannya mengalami kerugian ratusan juta dollar. Oleh sebab itu menarik sekali untuk untuk diteliti faktor penentu keberhasilan pengimplementasian sistem ERP.

Penelitian mengenai keberhasilan ERP telah dilakukan oleh peneliti seperti Poonam (2010) yang menunjukan bahwa strategi dan manajemen proyek berpengaruh terhadap keberhasilan implementasi ERP. Hayati et al., (2015) dan Winarno (2010) memiliki hasil bahwa teknologi, manajemen SDM dan manajemen proyek mempengaruhi kesuksesan implementasi ERP.

Pada penelitian ini peneliti memperbaharui dengan mengambil variabel manajemen prubahan (change management), manajemen proyek (project management), dukungan pimpinan puncak perusahaan (top management sponsorship), sebagai variabel bebas serta keberhasilan implementasi ERP sebagai variabel tetapnya.

Berdasarkan penjelasan di atas, maka permasalahan yang akan dibahas pada penelitian ini adalah:

1. Apakah faktor Manajemen Perubahan (Change Management) mempengaruhi keberhasilan implementasi ERP?

2. Apakah faktor Manajemen Proyek (Project Management) mempengaruhi keberhasilan implementasi ERP?

3. Apakah faktor dukungan pimpinan puncak perusahaan (Top Management Sponsorship) mempengaruhi keberhasilan implementasi ERP? 
4. Apakah faktor Manajemen Perubahan (Change Management), faktor Manajemen Proyek (Project Management), faktor dukungan pimpinan puncak perusahaan (Top Management Sponsorship), dalam proyek ERP secara bersama-sama / simultan mempengaruhi keberhasilan implementasi ERP?

Adapun tujuan dilakukannya penelitian ini adalah mengetahui pengaruh faktor Manajemen Perubahan (Change Management) terhadap keberhasilan implementasi ERP, mengetahui pengaruh faktor Manajemen Proyek (Project Management) terhadap keberhasilan implementasi ERP, mengetahui pengaruh faktor dukungan pimpinan puncak perusahaan (Top Management Sponsorship) terhadap keberhasilan implementasi ERP dan mengetahui semua faktor tersebut secara bersama-sama/simultan terhadap keberhasilan implementasi ERP. Penelitian ini diharapkan dapat mejadi masukan bagi perusahaan-perusahaan yang akan mengimplementasikan sistem ERP supaya berhasil. Penelitian ini lebih luas sampelnya dibandingkan dengan penelitian sebelumnya.

\section{Metode Penelitian}

Penelitian ini menggunakan desain riset ekploratori di bagian awal yang kemudian dilanjutkan dengan riset deskriptif. Pada tahap eksploratif, peneliti mencari gambaran umum mengenai implementasi ERP di Indonesia melalui berbagai media. Artikel dan studi pustaka yang ada dikumpulkan untuk memperoleh gambaran subyek yang diteliti seperti data company profile dari situs internet serta data lainnya yang berhubungan langsung dengan subyek penelitian. Selanjutnya dilakukan riset deskriptif dengan mengambil sampel dan dikelola secara beraturan dengan metode riset yang dianjurkan. Sampel yang diambil dengan metode non-probability sampling berdasarkan kriteria dari populasi keseluruhan karyawan yang bekerja sama dengan PT Innotek Indonesia. Berdasarkan Teknik tersebut, terpilihlah 80 responden yang terdiri dari 13 Direksi untuk masing-masing perusahaan partner, 16 Kepala Departemen, 18 Manajer dan 33 Staff (senior \& Junior). Setelah sampel ditentukan, peneliti mengambil mengambil data secara langsung kepada responden yang memiliki kemampuan dan kaitannya dengan implementasi sistem ERP pada PT Innotek Indonesia melalui kuesioner. Hasil pengumpulan data melalui kuesioner diolah dengan metode statistika deskriptif seperti mean, median varians dan modus.

Varabel independen dibentuk dari berbagai komponen yang diambil dari penelitian terdahulu. Atribut Change Management diambil dari penelitian Rosario (2000), Project Management diambil dari Shanks et al., (2000) dan Fitrah (2010), Top Management Sponsorship dari Bingi, Sharma, dan Godla (1999), Buckhout, Frey, dan Nemec (1999) dan Mary (1999). Atribut variabel tetap yakni Keberhasilan implementasi ERP diambil dari penelitian Fitrah (2010). Skala penelitian ini menggunakan 2 skala yakni nominal untuk data demografis dan skala likert (4 tingkatan) untuk bagian pertanyaan masing-masing atribut variabel.

Metode analisis dilakukan dengan Analisa deskriptif dan kuantitatif. Pada bagian deskripsi, dijelaskan mengenai peranan dan kontribusi keenam faktor sukses kritis dalam mempengaruhi keberhasilan implementasi ERP. Selain itu juga, analisis 
deskripsi digunakan dalam menganalisa demografi responden seperti usia, posisi atau jabatan, pendidikan terakhir, departemen tempat bekerja, dan nilai rata-rata untuk skala interval. Metode Analisa kuantitatif menggunakan program IBM SPSS dengan pengujian validitas, reliabilitas, analisis regresi linear berganda, dan terakhir pengujian hipotesis. Pengujian validitas menggunakan korelasi bivariate pearson dan nilai Cronbach's Alpha dalam pengujian reliabilitas.

Langkah dalam penelitian ini yang pertama adalah menentukan tujuan penelitian, melakukan observasi lapangan di lokasi penelitian serta studi literatur dari beberapa penelitian terdahulu sebagai referensi mengenai penentuan faktor-faktor yang mempengaruhi implementasi ERP, penentuan variabel yang mempengaruhi keberhasilan implementasi ERP yang telah ditetapkan berdasarkan observasi lapangan dan literatur yaitu variabel change management, project management, dan top management sponsorship dengan masing-masing atribut / indikator variabel yang ada berdasarakan dari referensi penelitian yang sudah ada. Menentukan dan menghubungi responden, kemudian melakukan wawancara dengan responden terpilih mengenai faktor-faktor yang mempengaruhi keberhasilan implementasi ERP. Melakukan tabulasi data dan terakhir membuat Analisa dari hasil pengujian data.

\section{Hasil dan Pembahasan}

Jumlah responden pada penelitian ini ada 80 orang dengan presentasi sumber informasi dari internet $14 \%$, artikel $14,18 \%$, bagian IT 18,22\%, praktisi independen ERP $6,7 \%$ dan vendor 31,39\%. Porsi terbesar informasi mengenai ERP pada penelitian ini adalah berasal dari vendor yang artinya vendor ERP lebih proaktif menginformasikan mengenai ERP pada perusahaan-perusahaan. Lamanya penggunaan ERP oleh responden paling banyak adalah lebih dari 5 tahun dengan porsi 43,54\%, penggunaan 3-5 tahun ada sebanyak 22\% dan 19\%1-3 tahun terakhir ada 5\% pengguna menggunakan ERP dibawah 1 tahun. Pada deskripsi lamanya penggunaan ERP dapat ditarik kesimpulan bahwa responden cukup lama mengenal ERP. Pada penelitian ini diketahui bahwa departemen paling banyak menjadi prioritas adalah departemen keuangan dengan presentase sebanyak $14,17 \%$. Selanjutnya diikuti oleh payroll $13 \%$, departemen logistic 12\%, HR sebesar 10,13\%, Distribusi sebesar 10\%, Pergudangan sebesar 9,11 \% IT sebesar 8,10\%, Produksi 6,8 \%, bagian umum 6,1\%. Sistem ERP yang memadukan semua bagian menjadikan banyak modul yang terintegrasi dengan modul keuangan. Pada penelitian ini juga dapat ditemukan bahwa persepsi umum mengenai implementasi ERP yang menunjukan bahwa $80 \%$ responden berpendapat bahwa implementasi ERP di tempatnya berhasil di implementasikan dan sisanya adalah gagal. Pada bagian usia responden peneliti mendapatkan bahwa pengguna ERP terbanyak adalah $40 \%$ pada usia 31-40 tahun pengguna selanjutnya adalah 20-30 tahun dengan angka 35\% kemudian 25\% pada usia 41-50 tahun. Pada usia pengguna tersebut terdapat $40 \%$ sebagai staf senior, $24 \%$ sebagai manajer, $20 \%$ manajer umum atau kepala departemen, dan $16 \%$ direksi. Pendidikan yang ditempuh oleng responden atau pengguna adalah $85 \%$ dari diploma sampai jenjang S1. Sisanya adalah SMA sederajat. 
Responden pengguna ERP dalam penelitian ini yang paling banyak adalah dari departemen keuangan sebanyak 30\% dan IT 30\%. Selanjutnya adalah HR dan personalia $10 \%$, terakhir logistic dan lainnya sebanyak $30 \%$. Responden yang diambil lebih banyak berlatar belakang keuangan dan manajemen serta praktisi.

Selanjutnya hasil dari pengujian validitas. Pengujian validitas ini menguji derajat ketepatan instrumen untuk mengumpulkan data penelitian. Pada penelitian ini pengujian validitas melihat angka signifikansi yang di bawah 0.05 maka akan disimpulkan valid dan dengan $\mathrm{r}$ tabel di bawah 0.2199. Nilai rtabel dengan $\mathrm{df}=78$ (diperoleh dari $\mathrm{N}-2=$ $80-2=78)$.

Tabel 1

Hasil Uji Validitas Change Management (CM)

\begin{tabular}{cccccc}
\hline $\begin{array}{c}\text { Pernyataan } \\
\text { ke }\end{array}$ & $\begin{array}{c}\text { Pearson } \\
\text { Correlation }\end{array}$ & r table & $\begin{array}{c}\text { Sig. (2 } \\
\text { tailed) }\end{array}$ & Standard & Validitas \\
\hline \multicolumn{7}{c}{$\mathrm{A}$} & $\mathrm{B}$ & & & $\mathrm{A}>\mathrm{B}$ \\
\hline 1 & 0.639 & 0.2199 & 0,00 & 0,05 & Absah \\
\hline 2 & 0.635 & 0.2199 & 0,00 & 0,05 & Absah \\
\hline 3 & 0.73 & 0.2199 & 0,00 & 0,05 & Absah \\
\hline 4 & 0.526 & 0.2199 & 0,00 & 0,05 & Absah \\
\hline \multicolumn{6}{l}{ Sumber: Hasil Pengolahan Data Primer (2020) } \\
\end{tabular}

Tabel 2

Hasil Uji Validitas Project Management (PM)

\begin{tabular}{cccccc}
\hline $\begin{array}{c}\text { Pernyataan } \\
\text { ke }\end{array}$ & $\begin{array}{c}\text { Pearson } \\
\text { Correlation }\end{array}$ & r table & $\begin{array}{c}\text { Sig. (2 } \\
\text { tailed) }\end{array}$ & Standard & Validitas \\
\hline 1 & $\mathrm{~A}$ & $\mathrm{~B}$ & & & $\mathrm{~A}>\mathrm{B}$ \\
\hline 2 & 0.559 & 0.2199 & 0,00 & 0,05 & Absah \\
\hline 3 & 0.538 & 0.2199 & 0,00 & 0,05 & Absah \\
\hline 4 & 0.565 & 0.2199 & 0,00 & 0,05 & Absah \\
\hline 5 & 0.503 & 0.2199 & 0,00 & 0,05 & Absah \\
\hline 6 & 0.501 & 0.2199 & 0,00 & 0,05 & Absah \\
\hline & 0.573 & 0.2199 & 0,00 & 0,05 & Absah \\
\hline
\end{tabular}

Sumber: Hasil Pengolahan Data Primer (2020) 
Tabel 3

Hasil Uji Validitas Top Management Sponsorship (TMS)

\begin{tabular}{cccccc}
\hline $\begin{array}{c}\text { Pernyataan } \\
\text { ke }\end{array}$ & $\begin{array}{c}\text { Pearson } \\
\text { Correlation }\end{array}$ & r table & $\begin{array}{c}\text { Sig. (2 } \\
\text { tailed) }\end{array}$ & Standard & Validitas \\
\hline & $\mathrm{A}$ & $\mathrm{B}$ & & & $\mathrm{A}>\mathrm{B}$ \\
\hline 1 & 0.758 & 0.2199 & 0,00 & 0,05 & Absah \\
\hline 2 & 0.635 & 0.2199 & 0,00 & 0,05 & Absah \\
\hline 3 & 0.822 & 0.2199 & 0,00 & 0,05 & Absah \\
\hline 4 & 0.726 & 0.2199 & 0,00 & 0,05 & Absah \\
\hline 5 & 0.824 & 0.2199 & 0,00 & 0,05 & Absah \\
\hline
\end{tabular}

Sumber: Hasil Pengolahan Data Primer (2020)

Berdasarkan hasil uji validitas diperoleh kesimpulan bahwa semua butir pertanyaan dari semua variabel disimpulkan valid dengan tingkat signifikansi 0,05 dan semua $r$ hitung lebih dari 0,2199. Pada pengujian reliabilitas, nilai Cronbach's Alpha dari hasil perhitungan tabel 5, semua variabel berkisar antara 0,706-0,919 atau dapat disimpulkan bahwa nilai alpha di atas 0,70. Berdasarkan hasil tersebut dapat disimpulkan bahwa instrumen yang digunakan bersifat reliabel. Artinya, instrumen berupa kuesioner dapat dikatakan memiliki tingkat keandalan dan konsistesi yang tinggi sehingga dapat dikatakan reliabel.

Tabel 4

Hasil Uji Reliabilitas Variabel Instrumen

\begin{tabular}{cccc}
\hline Variabel & $\begin{array}{c}\text { Cronbach's } \\
\text { Alpha }\end{array}$ & $\begin{array}{c}\text { Nilai } \\
\text { Standar }\end{array}$ & Kesimpulan \\
\hline Change Management $(C M)$ & 0.706 & 0,70 & Reliabel \\
\hline Top Management Sponsorship $(T M S)$ & 0.771 & 0,70 & Reliabel \\
\hline Project Management $(P M)$ & 0.723 & 0,70 & Reliabel \\
\hline
\end{tabular}

Sumber: Hasil Pengolahan Data Primer (2020)

Berdasarkan tabel 4 hasil uji regresi linear berganda dapat dibentuk persamaan sebagai berikut:

$$
\mathrm{Y}=-3.073+0.429 \mathrm{X}_{1}+0.931 \mathrm{X}_{2}+0.285 \mathrm{X}_{3}-0.489 \mathrm{X}_{4}+0.183 \mathrm{X}_{5}-0.076 \mathrm{X}_{6}+\mathrm{e}
$$

Dari persamaan regresi diatas dapat dilihat bahwa pengaruh Change Management terhadap Keberhasilan Implementasi ERP adalah positif. Pengaruh Project Management terhadap Keberhasilan Implementasi ERP adalah positif. Top Management Sponsorship terhadap Keberhasilan Implementasi ERP adalah positif. 
Tabel 5

Hasil Uji Regresi Linear Berganda

\begin{tabular}{|c|c|c|c|c|c|}
\hline \multirow{2}{*}{ Model } & \multicolumn{2}{|c|}{$\begin{array}{c}\text { Unstandardized } \\
\text { Coefficients }\end{array}$} & \multirow{2}{*}{$\begin{array}{c}\text { Unstandardized } \\
\text { Coefficients } \\
\text { Beta }\end{array}$} & \multirow{2}{*}{$\mathrm{t}$} & \multirow{2}{*}{ Sig. } \\
\hline & B & $\begin{array}{l}\text { Std. } \\
\text { Error }\end{array}$ & & & \\
\hline Constant & -3.073 & 2.5 & & -1.22 & 0.224 \\
\hline $\begin{array}{c}\text { Change } \\
\text { Management } \\
(\mathrm{CM})\end{array}$ & 0.429 & 0.17 & 0.22 & 2.661 & 0.011 \\
\hline $\begin{array}{c}\text { Project } \\
\text { Management } \\
(\mathrm{PM})\end{array}$ & 0.931 & 0.16 & 0.69 & 4.806 & 0.001 \\
\hline $\begin{array}{c}\text { Top } \\
\text { Management } \\
\text { Sponsorship } \\
\text { (TMS) }\end{array}$ & 0.285 & 0.14 & 0.18 & 2.124 & 0.019 \\
\hline
\end{tabular}

Sumber: Hasil Pengolahan Data Primer (2020)

Koefisien regresi pada Change Management adalah 0.429. Hal ini menunjukan bahwa apabila nilai koefisien regresi lainnya dipertahankan maka perubahan satu nilai Change Management akan memberi pengaruh positif sebesar 0.429 unit skor Keberhasilan Implementasi ERP dengan konstanta -3.073. Hipotesis pertama diterima, terdapat pengaruh yang signifikan antara faktor change management dengan keberhasilan implementasi ERP dinyatakan dengan nilai signifikansi faktor ini yang kurang dari 0.05, yaitu sebesar 0.013. Hasil ini konsisten dengan penelitian Arvidsson dan Kojic (2017), serta AlQashami dan Mohammad, (2015). Para responden berpendapat bahwa change management sangat penting untuk menunjang keberhasilan implementasi ERP. Manajemen perubahan yang terjadi juga harus mencakup seluruh siklus hidup proyek ERP. Ruang lingkup manajemen perubahan yang harus dikelola adalah orang, budaya dan organisasi. Faktor manusia berkaitan dengan motivasi dan penerimaan akan pentingnya perubahan dan bagaimana manusia menerima perubahan yang telah terjadi. Faktor organisasi melibatkan kebutuhan untuk mengubah peran, komitmen, dan tanggung jawab selama operasi proyek, dan perlu untuk mengubah struktur organisasi yang dirancang untuk mendukung implementasi ERP, atau di mana perubahan skala besar diperlukan karena reorganisasi sesuai dengan proses bisnis baru.

Hipotesis yang kedua diterima karena terdapat pengaruh yang signifikan antara faktor project management dengan keberhasilan implementasi ERP. Hal ini dinyatakan dengan nilai signifikansi faktor ini yang kurang dari 0.05, yaitu sebesar 0.000 dan sejalan dengan penelitian AlQashami dan Mohammad (2015), Tarhini, Ammar, Tarhini, dan Masa'deh (2015). Responden berpendapat bahwa project management dan atributnya adalah faktor yang sangat penting untuk menentukan keberhasilan implementasi ERP. Pada realisasinya di lapangan memang hampir semua user ERP adalah pengguna awal aplikasi ERP. Sehingga hal ini sangat bergantung pada petunjuk 
dan arahan project management office dalam melaksanakan proyek ERP. Kehadiran seorang Project Manager yang pintar dan berpengalaman dalam proyek ERP menjadi tumpuan dalam proyek ERP. Demikian juga dengan kemampuan project manager mengendalikan para stakeholder dan mengawal seluruh proses implementasi ERP merupakan faktor yang dilihat para responden menjadi penentu utama sukses proyek ERP.

Koefisien regresi Top Management Sponsorship sebesar 0.285 dapat diartikan bahwa apabila nilai koefisien regresi lainnya dipertahankan maka perubahan satu nilai skor Top Management Sponsorship akan memberi pengaruh positif sebesar 0.285 unit skor Keberhasilan Implementasi ERP dengan konstanta -3.073. Pengaruh yang positif ini sesuai dengan penelitian Al-Fawaz, Al-Salti, dan Eldabi (2008), Lestariningsih, Suyanto, dan Lutfi (2015). Jajaran manajemen puncak di sebuah perusahaan pengguna ERP memiliki peran yang penting saat menunjang keberhasilan implementasi ERP. Dukungan dilakukan dengan cara turun ke lapangan untuk memantau dan mengevaluasi secara langsung pelaksanaan implementasi ERP. Manajemen puncak harus mengambil keputusan strategik atas setiap masalah yang muncul kemudian menjadwalkan adalanya review secara berkala sebagai contoh dalam mingguan atau bulanan untuk memonitoring jalannya proyek ERP. Dukungan manajemen puncak tersebut akan sangat terasa dan menjamin keberhasilan implementasi ERP di perusahaan.

Tabel 6

Koefesien Regresi Linear Berganda (ANOVA)

\begin{tabular}{lcrrrr}
\hline \multicolumn{1}{c}{ Model } & $\begin{array}{c}\text { Sum Of } \\
\text { Squares }\end{array}$ & df & $\begin{array}{c}\text { Mean } \\
\text { Square }\end{array}$ & F & Sig. \\
\hline 1 Regeression & 463.756 & 6 & 77.293 & 25.367 & 0.00001 \\
Residual & 222.431 & 74 & 3.047 & & \\
Total & 686.187 & 80 & & & \\
\hline
\end{tabular}

Sumber: Hasil Pengolahan Data Primer (2020)

Hasil Uji F diperoleh angka sebesar 25.4 dengan tingkat signifikansi sebesar 0.000. Karena angka signifikansi 0.000 kurang dari 0.05, maka model Regresi Liniear Berganda ini juga dapat untuk digunakan dalam memprediksi Keberhasilan Implementasi ERP. Pada tabel 7 tersebut diketahui bahwa F hitung memiliki nilai 25.367 dan jika dibandingkan antara nilai $\mathrm{F}$ tabel dengan probabilitas 0.05 yakni 2.23, maka lebih besar F hitung daripada F tabel. Dengan kata lain, Change Management, Project Management, dan Top Management Sponsorship secara bersama-sama mempengaruhi Keberhasilan Implementasi ERP.

\section{Kesimpulan}

Berdasarkan hasil olah data yang dilakukan maka dapat diambil kesimpulan dari jawaban atas rumusan masalah dalam penelitian ini yakni vabial manajemen seperti Change Management dapat mempengaruhi keberhasilan ERP karena dengan adanya 
perubahan sistem, karyawan perlu diinformasikan mengenai perubahan ini. Project Management memiliki pengaruh yang positif dalam keberhasilan ERP, karena variabel ini sangat penting dalam proses membimbing karyawan dan mengawal proses ERP dari awal hingga akhir. Top Management Sponsorship sangat dibutuhkan dalam keberhasilan ini karena tanpa adanya komitmen dari pimpinan tertinggi maka ERP ini tidak akan berjalan dengan baik. Change Management, Project Management, dan Top Management Sponsorship secara bersama-sama juga mempengaruhi Keberhasilan Implementasi ERP. Pada penelitian selanjutnya bisa diteliti mengenai dampak keberhasilan penerapan ERP ini pada nilai perusahaanya. 


\section{BIBLIOGRAFI}

Al-Fawaz, K., Al-Salti, Zahran, \& Eldabi, Tillal. (2008). Critical success factors in ERP implementation: A review.

AlQashami, Ashwaq, \& Mohammad, Heba. (2015). Critical Success Factors (CSFS) of Enterprise Resource Planning (ERP) System Implementation in Higher Education Institutions (HEIS) : Concepts and Literature Review. In Computer Science \& Information Technology (Vol. 5). https://doi.org/10.5121/csit.2015.51508

Arvidsson, Jonathan, \& Kojic, Daniel. (2017). Critical Success Factors in ERP Implementation. Jönköping International Business School.

Bingi, Prasad, Sharma, Maneesh K., \& Godla, Jayanth K. (1999). Critical Issues Affecting an ERP Implementation. Information Systems Management, 16(3), 7-14. https://doi.org/10.1201/1078/43197.16.3.19990601/31310.2

Buckhout, S., Frey, E., \& Nemec, J. J. (1999). Making ERP succeed : turning fear into promise. IEEE Engineering Management Review, 116-123.

Fitrah, M. (2010). Faktor-faktor yang mempengaruhi keberhasilan implementasi Enterprise Resource Planning. Universitas Indonesia.

Gable, Guy G., Sedera, Darshana, \& Chan, Taizan. (2003). Enterprise systems success: a measurement model. In March, Salvatore T. and Massey, Anne and DeGross, Janice I., Eds. Proceedings Twenty-Fourth International Conference on Information Systems, 576-591.

Hayati, Enty Nur, Fitriyah, Mumpuni Wijiasih, Program, Dosen, Teknik, Studi, Fakultas, Industri, Stikubank, Universitas, Kendeng, Jalan, \& Ngisor, V. Bendan. (2015). Penerapan E-Supply Chain Management Pada Industri (Studi Kasus Pada PT Maitland-Smith Indonesia). 19-33.

Kanaracus, C. (2010). Biggest Failures of 2010.

Kimberling, E. (2015). Key Findings From the 2015 ERP Report. Colorado.

Krigsman, M. (2010). ERP failure: New research and statistics.

Lestariningsih, Tri, Suyanto, M., \& Lutfi, Emha Taufiq. (2015). Analisis Faktor-Faktor Keberhasilan Implementasi Sistementerprise Resource Planning (Studi Kasus : PT Teknika Sarana Gardian). Semnasteknomedia Online, 3(1), 331-336.

Mary, Sumner. (1999). Critical success factors in enterprise wide information management systems projects. Proceeding of the Americas Conference on InformationSystems(AMCIS),297-303.

https://doi.org/https://doi.org/10.1145/299513.299722 
Poonam, Garg. (2010). Critical Success factors for Enterprise Resource Planning implementation in Indian Retail Industry: An Exploratory study. International Journal of Computer Science and Information Security, 8.

Rosario, JG. (2000). On the leading edge: critical success factors in ERP implementation projects. Business World, 17, 15-29.

Sasmoyo. (2010). Enterprise Resource Planning (ERP) dan Implementasi Sistem Informasi Berbasis ERP.

Shanks, Graeme, Parr, Anne, Hu, Bin, Corbitt, Brian, Thanasankit, Theerasak, \& Seddon, Peter. (2000). Differences in Critical Success Factors in ERP Systems Implementation in Australia and China: A Cultural Analysis. In 2000 Citeseer.

Tarhini, Ali, Ammar, Hussain, Tarhini, Takwa, \& Masa'deh, Ra'Ed. (2015). Analysis of the Critical Success Factors for Enterprise Resource Planning Implementation from Stakeholders' Perspective: A Systematic Review. International Business Research, $8,25-40$.

Tjakrawala, Kurniawan, \& Lukita, Andreas. (2012). Model Kausalitas Critical Success Factors Dalam Implementasi Sistem Enterprise Resource Planning Guna Memberikan Nwt Benefit Bagi Perushaan Dengan Menggunakan Partial Least Square. Jurnal Dan Prosiding SNA - Simposium Nasional Akuntansi, 15(1), 1-33.

Toruan, Dewi Margaret. (2013). Kesuksesan dan Kegagalan Implementasi Enterprise Resources Planning (ERP) dan Contoh Studi Kasus PT Semen Gresik \& Fox Meyer. Institut Pertanian Bogor, Bogor.

Winarno, Wahyu. (2010). Kesuksesan Dan Kegagalan Implementasi Sistem Erp: Apakah Kesalahan Peranti Lunak? Jurnal Akuntansi Universitas Jember, 8. https://doi.org/10.19184/jauj.v8i1.1221 